\title{
Recent patents in obesity research
}

\author{
EP 954975 \\ WO 9955697 New indolyl derivatives and pharmaceutically acceptable salts, \\ ment in human food and animal feeds, and for treating obesity. \\ e.g., 2-(4-fluoro- ${ }^{1} \mathrm{H}$-indol-3-ylmethyl)-piperidin-1-yl)- $N$-pyridin- \\ 2-yl-acetamide, used to treat cognitive as well as central \\ nervous system disorders, including obesity. \\ WO 9954351 A novel transmembrane receptor protein that acts as an \\ activator or inhibitor of human $\mathrm{H} 218$, for use in the treatment \\ and diagnosis of disease. \\ WO 9952944 New isolated G-protein coupled receptor AXOR3 polypeptides, \\ used to develop products for treating pain, cancers, obesity, \\ anorexia, and neurological and neurodegenerative disorders. \\ WO 9953095 Polymorphic human genomic sequences and related allele- \\ specific probes and primers, useful for genetic analysis, e.g., \\ correlating disease polymorphisms (or disease susceptibility) \\ or other phenotypic traits (e.g., baldness, obesity, fertility, \\ strength, response to drugs, etc.).
}

WO 9953056 Novel glycoprotein as an adipogenesis inhibitory factor; capable of suppressing differentiation and/or maturation of adipocytes and useful for preventing or treating obesity.

WO 9952856 New methylpropionic acid derivatives useful for treating obesity, hyperglycemia, disease involving colon hyperkinesia, depression, pollakiuria, urinary incontinence, gallstones, or disease involving bile duct hyperkinesia.

DE 19816903 New dipeptide derivatives useful as neuropeptide $Y$ agonists and/or antagonists for treating cardiovascular disorders, coronary, cerebral or renal vasospasms, obesity, bulimia, and asthma.

WO 9952876 Azacycloalkane derivatives useful for the treatment of FR 2777566 diabetes, hyperglycemia, and obesity.

WO 9951600 New corticotropin-releasing factor (CRF1) antagonist and neuropeptide $\mathrm{Y}$ (NPY1) receptor antagonist used to treat affective (Branford, CT) disorders, anxiety, depression, obesity, infertility, and others.

WO 9951740 A new human fatty acid transport protein, hFATP, for screening inhibitors or enhancers; useful to regulate fatty acid metabolism and to treat cardiomyopathies, diabetes, or obesity.

JP 11279064 A hormone containing the external preparation composition dehydroepiandrosterone and one or more additives; useful for the prevention and treatment of cancer, obesity, diabetes, retroviral infectious diseases, hyperlipidemia, melancholia, memory disorder, and progressive necrosis.

\section{Assignee}

Conlinco

(Detroit Lakes, MN)

American Home

Products

(Madison, NJ)

SmithKline

Beecham

(Philadelphia, PA)

SmithKline

Beecham

(London)

Whitehead Inst.

Biomedical Res.

(Cambridge, MA)

Snow Brand Milk Products Co. Ltd. (Tokyo)

\section{Kissei Pharm.}

Co. (Japan)

Boehringer

Ingelheim

(Ingelheim,

Germany)

Synthelabo; Sanofi-S (France)

Neurogen

Janssen Pharm. Washington

(Seattle, WA)

Saitama Daiichi Seiyaku (Japan) (Belgium); Univ.

Bergsma DJ, Elshourbagy $\mathrm{N}$, Lane P, Li X,

$10 / 28 / 1999$

Mooney JL, Tsui $P$

Hill J, Medhurst A,

10/21/1999

Michalovich D,

Pangalos $\mathrm{M}$

Hudson T, Lander ES, 10/21/1999 Wang D

Goto M, Higashio K, Kinosaki M, Kobayashi F, Mochizuki S, Morinaga $\mathrm{T}$, Nakagawa $\mathrm{N}$, Nakakarumai T, Tomoyasu A, Tsuda E, Yamaguchi K. Yano K, Yasuda H

Akahane M,

Hirabayashi A,

Mukaiyama $\mathrm{H}$,

Muranaka $H$, Sato M,

Tamai T, Tanaka N

Dollinger H, Doods HN， 10/21/1999

Esser F, Gaida W,

Minm G, Rudolf K,

Schnorrenberg $\mathrm{G}$

Bedoya ZM,

$10 / 21 / 1999$

Diaz MJA

10/14/1999

Horvath RF,

Maynard GD

Auwerx J, Deeb SS,

Martin G, Nemoto M

10/14/1999

10/12/1999

WO 9949894 A method for the treatment of obesity or diabetes, especially type II Genentech (S. San Stewart TA, Tomlinson E

10/7/1999 diabetes in humans, comprising administering a gas 6 antagonist.

WO 9950295 New agouti-related protein analogs and their fragments, used for treating wasting syndromes, obesity, or other disorders involving hypothalamic control of feeding.
Gryphon Sciences Gantz I, Kent SBH,

10/7/1999
CA)
(S. San Francisco,

\section{Thompson DA}

Wilken J

Source: Derwent Information, Alexandria, VA. "The patents in the table are pending. The status of each application is slightly different from country to country. For further details, contact Derwent Information, 1725 Duke St., Suite 250, Alexandria, VA 22314. Tel: 1 (800) DERWENT (info@derwent.com). 